УДК 544.169

\title{
ВЛИЯНИЕ ВОДНОЙ СРЕДЫ НА СТРОЕНИЕ И РЕАКЦИОННЫЕ ХАРАКТЕРИСТИКИ МОЛЕКУЛЫ ИМИНОДИУКСУСНОЙ КИСЛОТЫ И ЕЕ ИОНОВ
}

\author{
(C) 2017 Б. М. Даринский, А. М. Семенов \\ Воронежский государственный университет, Университетская пл., 1, 394018 Воронеж, Россия \\ e-mail:andy_semenov@mail.ru \\ Поступила в редакцию 03.05.2017 г.
}

\begin{abstract}
Аннотация. Методом функционала плотности (B3LYP) в базисе 6-31G++(d,p) проведены компьютерные вычисления строения молекулы иминодиуксусной кислоты и ее одно- и двухзарядного анионов в пустоте и водном растворе. Показано, что стабильной структурой кислоты является ее цвиттер-форма. Представлены распределение зарядов, молекулярные орбитали для молекулы иминодиуксусной кислоты. Предложена модель влияния водной среды на геометрию и эффективные заряды. Отмечено влияние водной среды на диссоциацию молекулы иминодиуксусной кислоты.
\end{abstract}

Ключевые слова: иминодиуксусная кислота, анион, молекула воды, молекулярные орбитали, энергия связи, гидроксоний.

\section{ВВЕДЕНИЕ}

Фрагменты иминодиуксусной кислоты (ИДУК) (формула $\mathrm{HN}\left(\mathrm{CH}_{2}-\mathrm{COOH}\right)_{2}$ ) используются в качестве адсорбента в ионообменниках АНКБ-50, которые считаются перспективными материалами для ионообменной хроматографии. В частности, в [1] они применялись для селективного извлечения палладия из электролитов аффинажа серебра. Молекулы ИДУК относятся к классу хелатирующих агентов, имеющим различное сродство к различным ионам комплексообразователей, что позволяет надеяться на их высокую селективность при применении в целях ионообменной хроматографии.

Термодинамические и кинетические характеристики процесса сорбции металлов на ионообменнике существенно зависят от влияния растворителя, в рассматриваемом случае - воды. Влияние молекул воды на энергию связи адсорбированного иона исследовано в ряде работ [2-3], в которых отмечается изменение ее с изменением количества молекул в ближайшем окружении. Целью настоящей работы явился квантово-химический расчет возможных конфигураций различных форм иминодиуксусной кислоты (цвиттер-ион, одно- и двухзарядный анионы) в отсутствие воды и в водном растворе, который рассматривается как диэлектрическая среда.

\section{ЭКСПЕРИМЕНТАЛЬНАЯ ЧАСТЬ}

Компьютерные вычисления структур и энергий в настоящей работе проводились с использованием программных пакетов Gaussian и GaussView. Выбор расчетного метода B3LYP/6-31G++(d,p) обусловлен описанным в работе [4] наилучшим согласием экспериментальных и вычисленных энергетических характеристик комплексов металлов с органическими лигандами.

Рассчитаны энергии и структуры следующих атомных кластеров:

- молекула иминодиуксусной кислоты в пустоте и водной среде;

- одно- и двухзарядный анионы молекулы иминодиуксусной кислоты в пустоте и в водной среде.

Установлена физико-химическая причина устойчивости цвиттер конфигурации, заключающаяся в том, что один из атомов водорода занимает такое положение в молекуле, что возникает замкнутое кольцо из электронных орбиталей, стабилизирующих эту конфигурацию.

\section{ОБСУЖДЕНИЕ РЕЗУЛЬТАТОВ}

\section{Структура молекулы и ионов}

Рассчитаны равновесные конфигурации с наименьшей энергией и найдены численные значения полных энергий для всех атомных кластеров, указанных выше. Энергия дополнительной стабилизации, представляющая собой разность между энергией атомного комплекса в вакууме и в водной среде, представлена в табице.

Из таблицы видно, что водная среда увеличивает стабильность молекулы и ионов ИДУК. Сравне- 
ние этих энергий показывает, что водная среда увеличивает энергию связи атомных кластеров, которая значительно растет с увеличением заряда иона. Для объяснения этого результата на качественном уровне можно воспользоваться представлениями о влиянии диэлектрической проницаемости среды на энергию и волновую функцию электронов, развитых в физике твердого тела. Первое явление, которое следует принять во внимание, представляет собой возникновение экситонов, для которых в настоящее время сложилось продвинутое научное направление [5-7]. Механизм влияния диэлектрической проницаемости среды заключается в ослаблении электрического поля, порождаемого ядрами атомов, удерживающих около себя электроны, находящиеся в связанном состоянии около положительного заряда. Особенно сильно этот эффект проявляется для экситонов большого радиуса, в несколько раз превосходящего расстояние между соседними атомами в среде. В этом случае эффективный заряд ядра и его электрический потенциал уменьшается в $\varepsilon$ раз (для воды $\varepsilon=81$ ). Ослабление ядерного электрического поля приводит к уменьшению энергии связи молекулы или иона. В рассматриваемом случае больших атомных кластеров этот эффект также присутствует, но ослаблен из-за локализованного характера молекулярных орбиталей.

Вторым эффектом является квантовомеханический эффект самолокализации свободного электрона в диэлектрической среде. Этот эффект возникает из-за того, что свободный электрон, как элек- трически заряженная частица, поляризует диэлектрическую среду. В результате он собирает вокруг себя избыточный положительный заряд и создает потенциальную яму, в которой сам оказывается в локализованном связанном состоянии, имеющим отрицательную энергию. Это свойство электрона положено в основу для объяснения поляронного эффекта возникновения решетки Вигнера и волн зарядовой плотности [8-10]. Если электрон находится в связанном состоянии в области действия притягивающих сил, то поляризация среды углубляет суммарную потенциальную яму и понижает его энергию. Окружение молекулы ИДУК водной диэлектрической средой сопровождается поляризацией этой среды с выделением зарядов противоположного знака в окрестности каждого атома, входящего в состав ИДУК. При этом происходит дополнительная поляризация атомов кислоты и увеличение эффективных зарядов ядер, рис. 1, 2.

Этот эффект приводит к усилению электростатической компоненты притяжения в каждой паре атомов, находящихся на каждой химической связи, и приводит к увеличению энергии связи молекулы в целом. Топологическое строение молекулы при этом сохраняется, но претерпевает деформацию. Расстояния между соседними атомами углеродно-азотного каркаса уменьшаются на величину в среднем около десятых долей процента. Расстояние между крайними атомами углеродного скелета уменьшается несколько больше, а именно, от 4.63237 до $4.54096 \AA$, относительное укороче-

Таблица 1. Энергии дополнительной стабилизации атомных кластеров при погружении в водную среду

[Table 1. The energy of additional stabilization of atomic clusters at immersed in an aqueous medium]

\begin{tabular}{|c|c|c|c|}
\hline $\begin{array}{c}\text { Форма ИДУК } \\
\text { [Structure of iminodiacetic acid molecule] }\end{array}$ & $\begin{array}{c}\text { Нейтральная } \\
\text { молекула } \\
\text { [Neutral molecule] }\end{array}$ & $\begin{array}{c}\text { Однозарядный aнион } \\
\text { [Single-charged anion] }\end{array}$ & $\begin{array}{c}\text { Двухзарядный анион } \\
\text { [Double-charged } \\
\text { anion] }\end{array}$ \\
\hline $\begin{array}{c}\text { Энергия стабилизации, кДж/моль } \\
\text { [The energy of stabilization, } \mathrm{kJ} / \mathrm{mol}]\end{array}$ & 53.88 & 244.46 & 762.1 \\
\hline
\end{tabular}

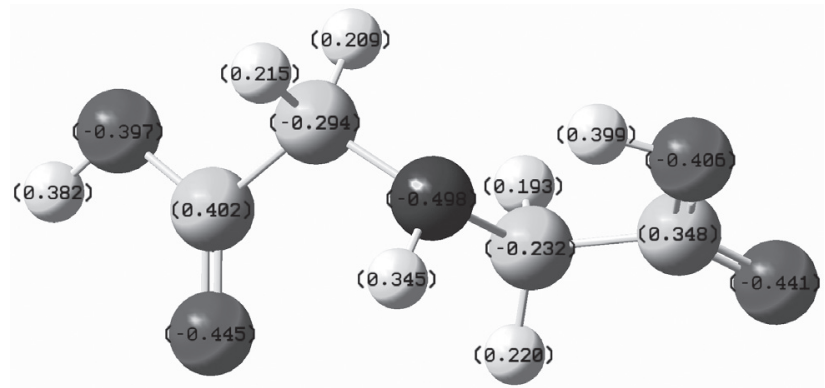

Рис. 1. Эффективные электрические заряды атомов ИДУК в вакууме

[Fig. 1. Effective electric charges of atoms of the iminodiacetic acid in vacuum]

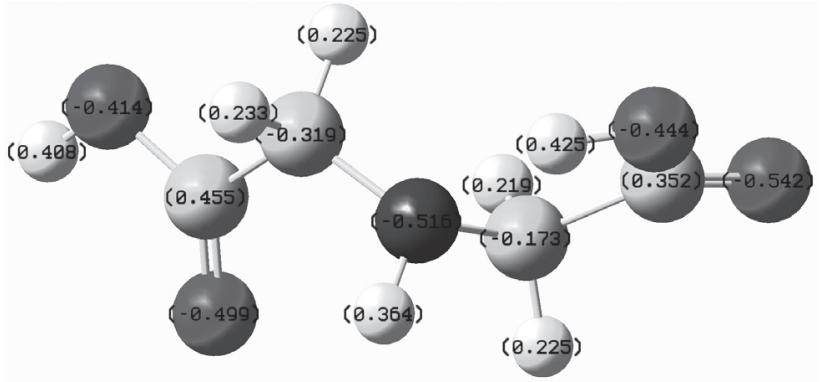

Рис. 2. Эффективные электрические заряды атомов ИДУК в водной среде

[Fig. 2. Effective electrical charges of the iminodiacetic acid atoms in an aqueous medium] 
ние составляет $2.5 \%$. Такая разница обусловлена уменьшением валентных и пространственных углов между соседними связями. Изменение двугранного угла, характеризующего поворот в цвиттер-группе, по расчетным данным оказалось самым большим и составило величину $22^{\circ}$. Этим, в основном, обусловлено уменьшение расстояния между крайними атомами углерода в углеродно-азотном каркасе. Наибольшее сокращение расстояния достигается между атомом азота и цвиттер-атомом водорода (от 1.944363 до $1.81675 \AA$ ).

\section{Орбитальный анализ}

В молекуле ИДУК имеется 35 электронных пар. Все валентные орбитали имеют доминирующую компоненту, которая связывает только два атома, и представляются несимметричными волновыми функциями, что свидетельствует о наличии ионной компоненты в каждой связи. Такая ситуация сохраняется после помещения молекулы в водную среду. Глубокие остовные орбитали локализованы около соответствующего атома, но имеют разные энергии для одинаковых элементов, занимающих разные позиции в молекуле. Помещение молекулы в водную среду уменьшает их энергию, поэтому следует полагать, что поляронный эффект для этих электронов преобладает над поляризационным, что приводит к дополнительной стабилизации молекулы.

Отметим следующие результаты для валентных орбиталей:

1. Энергии большинства орбиталей в порядке возрастания энергии с возрастанием номера орбиталей уменьшаются при помещении молекулы ИДУК в водную среду. Для небольшого количества орбиталей происходит небольшое увеличение энергии.

2. При помещении молекулы в водную среду происходит смена упорядочения множества орбиталей по возрастанию номера и, соответственно, ее энергии. Этот эффект объясняется разным влиянием поляризации среды на орбитали, имеющие различные положения в молекуле.

3. Имеется молекулярная орбиталь, которая связывает атомы азота и цвиттер-водорода. В молекуле ИДУК в пустоте она идет под № 32, а водной среде - № 33. Можно полагать, что физико-химическая причина устойчивости цвиттер конфигурации заключается в том, что один из атомов водорода занимает такое положение в молекуле, что возникает замкнутое кольцо из валентных электронных орбиталей, стабилизирующих эту конфигурацию. Интересно отметить, энергия этой орбитали в пустоте -0.33944 оказывается меньше соответствующей энергии в воде -0.31953 . Поэтому следует по- лагать, что водная среда ослабляет стабильность цвиттер-комплекса. Изображение этой орбитали представлено на рис. 3.

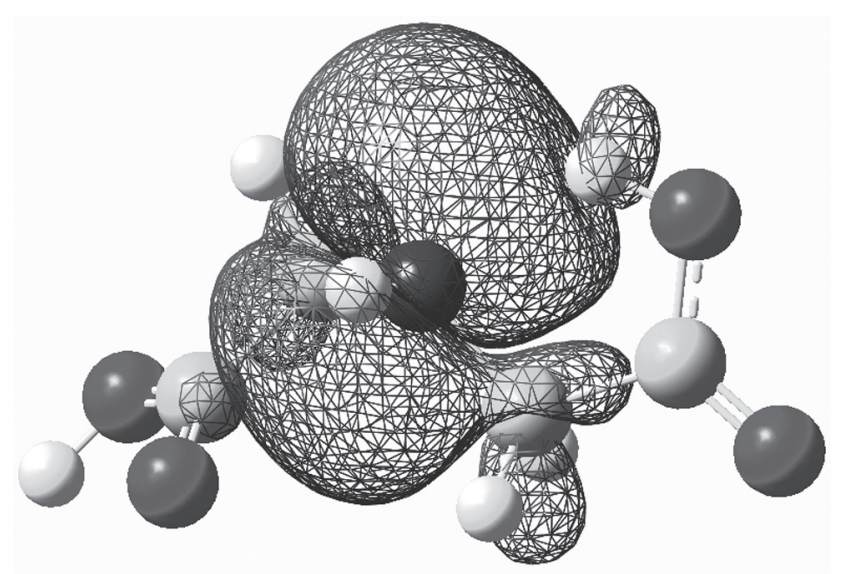

Рис. 3. Орбиталь № 32 ИДУК в вакууме, изображающая ковалентную связь между атомом азота и цвиттер-водорода

[Fig. 3. Orbital No. 32 of the iminodiacetic acid molecule in vacuum, depicting the covalent bond between a nitrogen atom and a zwitter-hydrogen atom]

Для изучения влияния молекул воды как химического фактора были проведены аналогичные вычисления для гидрата ИДУК с одной молекулой воды. Результаты этого численного эксперимента указывают на следующие закономерности:

Заметное изменение зарядов отдельных атомов молекулы ИДУК происходит вблизи молекулы воды. В удаленных атомах эти изменения незначительны. Аналогичная закономерность имеет место для структурных характеристик: расстояний между соседними атомами, валентных и двугранных углов:

1. Все орбитали изменяют свою энергию при добавлении молекулы воды. Орбитали, не являющиеся соседними к молекуле воды, увеличивают свою энергию относительно мало (на тысячные доли атомных единиц). Орбитали, примыкающие к молекуле воды, имеют уменьшенные энергии на сотые доли атомных единиц энергии.

2. Происходит изменение упорядочения по возрастанию энергии орбиталей.

3. Орбитали, локализованные на молекуле воды, имеют номера 16, 17, 29 и 34 и, таким образом, занимают промежуточную позицию между орбиталями молекулы ИДУК.

4. Имеется молекулярная орбиталь с № 32, которая связывает атомы кислорода в молекуле воды с ближайшим атомом водорода. Она сформирована из $p$-орбитали кислорода молекулы воды и $s$-орбитали атома водорода молекулы ИДУК, что свидетельству- 
ет о наличии водородной связи между этими атомами. Расстояние между атомом кислорода, принадлежащего молекуле воды, и атомом водорода составило $1.74 \AA$, короткое расстояние составило $0.99 \AA$.

\section{Диссоциация молекулы ИДУК в воде}

Для нахождения степени диссоциации была вычислена разница энергий молекулы ИДУК и продуктов распада. Примем во внимание следующую реакцию с образованием дианиона ИДУК:

ИДУК $\left(\mathrm{H}_{2} \mathrm{O}\right)_{2}+2 \mathrm{H}_{2} \mathrm{O} \rightarrow$ ИДУК ${ }^{-2}\left(\mathrm{H}_{2} \mathrm{O}\right)_{2}+2 \mathrm{H}^{+}\left(\mathrm{H}_{2} \mathrm{O}\right)$.

В этом процессе учитывается гидратация молекул кислоты и ее аниона двумя молекулами воды, наиболее сильно связанными с молекулой кислоты в положениях, полученных в результате расчета.

Рассмотрим условие равновесия компонентов реакции. Совокупность реагентов можно рассматривать как двухкомпонентную систему, в которой одной из компонент является гидрат ИДУК $\left(\mathrm{H}_{2} \mathrm{O}\right)_{2}$, второй - ИДУК $-\left(\mathrm{H}_{2} \mathrm{O}\right)_{2}+2 \mathrm{H}_{3} \mathrm{O}^{+}$. В условиях равновесия их химические потенциалы одинаковы, полагая, что концентрации молекул реагентов малы, получим:

$$
E_{0}+k T \ln \left(n_{0}\right)=E_{1}+3 k T \ln \left(n_{1}\right),
$$

здесь $E_{0}$ и $E_{1}-$ энергии ИДУК $2\left(\mathrm{H}_{2} \mathrm{O}\right)+2\left(\mathrm{H}_{2} \mathrm{O}\right)$ и ИДУК- $\left(\mathrm{H}_{2} \mathrm{O}\right)_{2}+2 \mathrm{H}_{3} \mathrm{O}^{+}, n_{0}$ и $n_{1}$ их относительные концентрации. Отсюда получается соотношение между этими концентрациями:

$$
\frac{n_{1^{3}}}{n_{0}}=\exp \left(\frac{E}{k T}\right)
$$

здесь $E=E_{0}-E_{1}$, расчет этой энергии реакции в водной среде привел к величине в несколько электронвольт. Учет влияния среды привел к увеличению $E$, что свидетельствует о содействии среды на диссоциацию молекул кислоты. При этом основной вклад в этот эффект вносится молекулами гидроксония.

В заключении отметим основные результаты работы. Стабильная структура молекулы ИДУК в газовой и водной среде представляется цвиттеризомером. Водная среда оказывает влияние на геометрию молекулы ИДУК, приводя к некоторым изменениям длин валентных связей и углов, несколько увеличивает эффективные заряды. Имеет место изменение порядка орбиталей и их энергетических уровней. Однако оно не приводит к радикальному изменению их структуры и появлению новых изомеров. Для более адекватного понимания влияния водного окружения следует учесть эффекты гидратации путем расчета характеристик молекул реагентов, находящихся в прямых контактах с молекулами воды. Увеличение степени распада молекул ИДУК на ионы в водной среде в основном определяется изменением энергии молекул гидроксония, возникающих в результате распада.

\section{СПИСОК ЛИТЕРАТУРЫ}

1. Лебедь А. Б, Маковская О. Ю., Скороходов В. И., Набойченко С. С., Мальцев С. К. // Химия в интересах устойчивого развития, 2011, т. 19, с. 535-540.

2. Даринский Б. М., Селеменев В. Ф., Флягина Е. М. // Сорбиионные и хроматографические проиесcbl, 2014, т. 14, №. 6, с. 933-938.

3. Салдадзе К. М., Копылова-Валова В. Д. Комплексообразующие иониты: (комплекситы). М.: Химия, 1980, $336 \mathrm{c}$.

4. Antony J., Hansen B., Hemmingsen L., Bauer R. // J. Phys. Chem. A, 2000, vol. 104, pp. 6047-6055.

5. Агранович В. М. Теория экситонов. М.: Наука, $1968,382 \mathrm{c}$

6. Давыдов А. С. Теория твердого тела. М.: Наука, $1976,640 \mathrm{c}$.

7. Экситоны. / Сб. статей под ред. Аграновича В. М. и Марадудина А. А. М.: Наука, 1985, 620 с.

8. Лахно В. Д., Чуев Г. Н. // УФН, 1995, т. 165, № 3, c. $285-298$.

9. Wigner E. // Phys. Rev. 1934, vol. 46, p. 1002.

10. Булаевский Л. Н. // УФН, 1976, т. 120, с. 259271.

\title{
INFLUENCE OF WATER MEDIUM ON THE STRUCTURE AND REACTION CHARACTERISTICS OF THE MOLECULE OF IMINODIACETIC ACID AND ITS IONS
}

\author{
(C) 2017 B. M. Darinskii, A. M. Semenov
}

\author{
Voronezh State University, 1 Universitetskaya sq., 394018 Voronezh, Russia \\ e-mail:andy_semenov@mail.ru \\ Received 03.05.2017
}

\begin{abstract}
Object under examination: Iminodiacetic acid has amphoteric and complexing properties. Its molecules have a chelate structure, which explains its specific characteristics in reactions with different reagents.
\end{abstract}


The use of iminodiacetic acid as a base material for chelate ion exchangers of type ANKB-50 opens the possibility of creating selective ion exchangers and separating reagents with similar chemical characteristics.

Topic: The atomic and electronic structure of iminodiacetic acid molecules in vacuum and water mediums was calculated. The mechanisms of how the dielectric water medium influenced the structural parameters were noted. The origin of the zwitterionic structure of the molecule and the influence of the water medium on it were explained. The influence of the polarization effect of the water medium on the dissociation of acid molecules was described.

Research method: Computer calculations of the molecular structure were carried out by B3LYP method, based on the density functional theory with the $6-31 \mathrm{G}++(\mathrm{d}, \mathrm{p})$ basis.

Results: The effect of a solvent as a continuous medium does not significantly alter the structure of the molecule. However it leads to a few shifts in the energy levels of the single-particle orbitals. The influence of the water medium leads to an increase in the stabilization energy of the molecule of iminodiacetic acid, as well as its anion and dianion. It increases as ion charge increases. It was established that the water medium increases the effective charges of all atoms. For the first time, attention was paid to the change in the energy of single-particle orbitals and their sequence as a result of water medium polarization. These effects were explained.

Scope: Computer calculations of the structure of the molecule of iminodiacetic acid and its anions in vacuum and water mediums were made. It was proved that the molecule has a zwitter form. The charge distribution and atomic orbitals of the molecule were presented. A model based on the influence of the aqueous environment on the geometry and effective charges was proposed. The role of the water medium in the dissociation of the molecule of iminodiacetic acid was noted.

Keywords: iminodiacetic acid, anion, water molecule, molecular orbitals, binding energy, hydroxonium.

\section{REFERENCES}

1. Lebed'A. B, Makovskaja O. Yu., Skorohodov V. I., et al. Chemistry for Sustainable Development, 2011, vol. 19, pp. 535-540.

2. Darinskij B. M., Selemenev V. F., Fljagina E. M. Sorption and Chromatographic Processes, 2014, vol. 14, p. 933. (in Russian)

3. Saldadze K. M., Kopylova-Valova V. D. Complexing Ionites: (Complexites). Moscow: Chemistry Publ., 1980, $336 \mathrm{p}$.

4. Antony J., Hansen B., Hemmingsen L., et al. J. Phys. Chem. A, 2000, vol. 104, p. 6047. DOI http://dx.doi. org/10.1021/jp993766
5. Agranovich V. M. Theory of Excitons. Moscow: Nauka Publ., 1968, 382 p.

6. Davydov A. S. Solid State Theory. Moscow: Nauka Publ., 1976, 640 p.

7. Excitons / Eds. by Agranovich V. M. and Maradudina A. A. Moscow: Nauka Publ., 1985, 620 p.

8. Lakhno V. D., Chuev G. N. Phys. Usp., 1995, vol. 38 p. 273 DOI: $10.3367 / \mathrm{UFNr} .0165 .199503$ c.0285

9. Wigner E. Phys. Rev., 1934, vol. 46, p. 1002. DOI: 10.1103/PhysRev.46.1002

10. Bulaevskii L. N. Phys. Usp., 1976, vol. 19, p. 836. DOI: 10.1070/PU1976v019n10ABEH005338
Даринский Борис Михайлович - д. ф.-м. н., профессор кафедры материаловедения и индустрии наносистем, Воронежский государственный университет; e-mail: darinskii@mail.ru

Семенов Андрей Михайлович - аспирант кафедры материаловедения и индустрии наносистем, Воронежский государственный университет; e-mail: andy_ semenov@mail.ru
Darinskii Boris M. - Dr. Sci. (Phys.-Math.), Full Professor, Department of Material Science and Industry of Nanosystems, Voronezh State University; e-mail: darinskii@ mail.ru

Semenov Andrey M. - postgraduate student, Department of Material Science and Industry of Nanosystems, Voronezh State University; e-mail: andy_semenov@mail.ru 